\title{
Innovative Trends in the Process Modelling of International Strategies: Systematic of Fundamental Factor Models
}

\author{
Lidiia Karpenko \\ Department of the Economic \\ and Financial Policy, \\ Odessa Regional Institute for Public \\ Administration of the National \\ Academy for Public Administration \\ under the President of Ukraine \\ Odessa, Ukraine \\ Lidiiako888@gmail.com \\ http://orcid.org/0000-0002-2888-2477 \\ Pavlo Pashko \\ University of the State Fiscal Service of \\ Ukraine, \\ Irpin, Ukraine \\ http://orcid.org/0000-0002-2697-751X
}

\author{
Pavlo Voronzhak \\ Department of Tax Policy, \\ University of the State Fiscal Service \\ of Ukraine, \\ Irpin, Ukraine \\ voronzak@gmail.com \\ http://orcid.org/0000-0001-9427-7905
}

\author{
Oksana Zhylinska \\ Department of Management \\ of Innovation and Investment Activities, \\ Taras Shevchenko National University \\ of Kyiv, \\ Kyiv. Ukraine \\ Lidako@list.ru \\ http://orcid.org/0000-0001-8366-0474
}

\begin{abstract}
This paper investigates the innovative trends in the process modelling of international strategies in the coordinates of globalization changes and European integration, such as: maximizing the geometric mean return, the systematic fundamental factor models, the output and inputs of a factor model, Barra E2 model risk index definitions, fundamental factors and market sensitive factor definitions for Wilshire atlas factor model. The methodological platform for effective elaboration of building strategic programs tactics of territories development is proposed in the work. Three types of factor models (statistical, macroeconomic and fundamental) for evaluating investment processes and justifying the development of international strategies, their variability and optimality are examined. In the article there are main vectors in the process modelling of international strategies, innovative forms of investment which are used widely: crowdfunding, crowdinvesting, crowdsourcing. Empirical and theoretical solutions allow to assess the process modelling of international strategies and optimize the choice of managerial decisions based on innovative dominants of economic development.
\end{abstract}

Keywords - factor models, the geometric mean return, international strategies, crowdfunding, crowdsourcing, crowdinvesting.

\section{INTRODUCTION}

Principal conditions of economic development are accumulated research and technology, industrial, investment potential, institutional impact on technological progress and state support of innovative transformations. Economic deformations prove expediency for activating and increasing of innovation investment processes efficiency in the industry and minimization of impact of factors slowing them down. Considerable impact on innovation investment activity, market dominance, compositeness in the industry has capacity of innovation potential. Under these conditions, the study of theoretical principles and practical measures concerning the development of domestic production by means of implementation of its innovative potential assumes significance. One of the most important and most complex elements in the process modelling system of the strategy is the provision of performance evaluation in specific time and place conditions on the market, and success also depends largely on the degree and effectiveness of interaction of all stakeholders of strategic planning in order to achieve the goals outlined and declared in the strategic plans for the development of economic systems. According to the theory of strategic planning, the realization of possible steps and corresponding instruments on the path of movement toward a strategic goal is reflected in the choice of adequate mechanisms for implementing strategies, which must necessarily be spelled out in strategic plans, and, accordingly, act as a non-integral element of the development process.

The global challenges of today, especially in the context of mainstreaming the issue of decentralization of management, require a review of traditional approaches to strategy development, strategic planning, primarily in the direction of a reorientation toward the development of strategic plans for the development of basic planning units, as well as the processing of strategies for the development of socio-economic systems on a meso-level through optimization, publicity, dialog and coherence of interests of all stakeholders. Taking into account the relevance of the problems, the theoretical, methodological and practical bases of the process modelling of international strategies, the conceptual basis of the formation of a holistic system of strategic planning of socio-economic development taking into account the world experience are studied. 


\section{LITERATURE REVIEW}

The analysis of the best international and European practices, scholar's publications show a variety of approaches to process modelling of international strategies on the platform systematic of fundamental factor models.

Studies of domestic and foreign scientists of economists testify to significant developments in the sphere of strategy of activation of innovative investment development, investment controlling in coordinates of financial and economic security, economic and mathematical modelling of development of territories, application of innovative methods of industrial development, features of the European investment market. For example, Hilorrme T., Fedoruk O., ShevchenkoI., Drobyazko, S. present innovative methods for the development of industries [4] . Fabozzi F. explores investment management [2]. Authors like Elton E., Gruber M., Brown S. and Goetzmann W. investigate the question of modern portfolio theory and investment analysis [1]. Piarce J., for instant, had dedicated his works to strategic management, formulation, implementation, and control [8]. Karpenko L. and Voronzhak P. are working on the issues of base alternatives and the paradigm of impact investing development in the coordinates of globalization changes and euro integration [10]. Some economists, such as Lipkova L., Kovarova E., Navratil B. explore development issues of innovation policy of the European Union and West Africa $[6 ; 9 ; 12]$. Stanickova M. explores the assessment of efficiency in selected EU member states by data envelopment analysis models [7]. In total, analysis of the recent scientific materials indicates the results of strategy of innovative investment development activation. A number of researches are devoted to problematic issues of attracting investors at an initial stage of implementation of the project, process modelling of international strategies.

\section{PROBLEM DESCRIPTION}

The purpose of the paper is to study the innovative trends in the process modelling of international strategies in the coordinates of globalization changes and European integration; analysis and characterization of the investment control management steps, such as: maximizing the geometric mean return, the systematic fundamental factor models, the output and inputs of a factor model, Barra E2 Model Risk Index Definitions, Fundamental factors and market sensitive factor definitions for Wilshire atlas factor model. The conceptual bases for the development of strategic planning programs in international business are examined. Three types of factor models and characteristic of their application for evaluating investment processes and justifying the development of international strategies, their variability and optimality are proposed. The application of new mechanisms of innovative development of the economy and its investment support is justified. In the article there are main vectors in the process modelling of international strategies, innovative forms of investment which are used widely: crowdfunding, crowdinvesting, crowdsourcing. Theoretical and methodological basis of the research consist of the research of modern economic concepts of management, informatization, economic and mathematical modelling. The objective of research consists in defining programmatic and methodological basic concepts for analysis of innovation activity, systematization of analytic indicators of enterprises.

\section{RESULTS AND DISCUSSION}

The process of strategic planning is the forecasting of the company's social and economic development, the search for new opportunities, the choice of strategies. As the main tool of strategic planning, one can distinguish the process of forming strategies, interpreted as the concept of creating and using a competitive advantage to prevent and suppress the efforts of competitors directed against the firm. Strategy is a guide to the achievement of the goals set and the realization of the organization's mission. Strategy formation is always associated with the problem of choosing alternative solutions. Without a strategy, the organization is unable to compete effectively: its actions will not meet the changed conditions and contribute to solving unexpected problems. There are four levels of strategy formation: the corporate strategy, the strategy of industries congeners group, functional strategies and operational strategists. The high level of economic development, as shown by the experience of the industrial countries of the world, is provided by a number of innovative transformations [1].

Lets begin our research with factor models. There are three types of factor models being used today to manage equity portfolios: statistical factor models, macroeconomic factor models, and fundamental factor models [2;3;10]. We have special scientific interest for studding the next modern direction such as maximizing the geometric mean return. This allows creating the process modelling of international strategies, taking into account the current trends in the development of territories. One alternative to utility theory is simply to select that portfolio that has the highest expected geometric mean return. Many researchers have put this forth as a universal criterion $[1 ; 2 ; 8]$. We have a special scientific interest in studying the following modern direction, such as maximizing the geometric mean return. This allows creating a process for modelling international strategies, taking into account current trends in the development of territories. The theory of utility suggests a possible development vector - the choice of a portfolio with the highest geometric mean return as expected. Most economists adhere to the point of view of the principle of universality by this criterion. The proponents have also argued that the maximum geometric mean: has the highest probability of reaching, or exceeding, any given wealth level in the shortest possible time; the highest probability of exceeding any given wealth level over any given period of time.

These characteristics of the maximum geometric mean portfolio are extremely appealing and have attracted many advocates $[4 ; 5 ; 6]$. A certain group of theorists reject the criterion estimate of geometric average profitability, since it is believed that investors put a primary goal to maximize the expected usefulness of marginal wealth, and thereby they accept the principles of utility theory. The geometric mean is easy to define. Instead of adding together the observations to obtain the mean, we multiply them [2]. If $R_{i j}$ is the $i$-th possible return on the $j$-th portfolio and each outcome is equally likely, then the geometric mean return on the portfolio $\bar{R}_{G j}$ is:

$$
\begin{aligned}
& \bar{R}_{G j}=\left(1+R_{1 j}\right)^{1 / N} \times\left(1+R_{2 j}\right)^{1 / N} \times \ldots \times \\
& \times\left(1+R_{N j}\right)^{1 / N}-1.0
\end{aligned}
$$


If the likelihood of each observation is different and $P i j$ is the probability of the $i$-th outcome for portfolio $j$, then the geometric mean return is:

$$
\begin{aligned}
& \bar{R}_{G j}=\left(1+R_{1 j}\right)^{P_{1 j} \times\left(1+R_{2 j}\right)^{P_{2 j}} \times \ldots \times} \\
& \times\left(1+R_{N j}\right)^{P} N j-1.0
\end{aligned}
$$

This is sometimes written in compact form. The symbol tt means product. Thus, the above series can be written as:

$$
\bar{R}_{G j}=\prod_{i=1}^{N}\left(1+R_{1 j}\right)^{P} i j-1.0
$$

The portfolio that has the maximum geometric mean is usually a diversified portfolio. This can be illustrated with an example. In the Table 1 we are going to show three possible investments listed as securities A, B, and C. Each of these investments has two possible outcomes, each equally likely. The portfolio shown consists of equal proportions of each of the three securities. As can be seen from the table, the portfolio has a higher geometric mean return than any of the individual securities. This result is easily explained. The geometric mean return penalizes extreme observations. In fact, a strategy with any probability of bankruptcy would never be selected as it would have a zero geometric mean. As we have seen in other chapters, portfolios have less extreme observations than individual securities. Thus, the geometric mean strategy usually leads to a diversified strategy [1;231-232].

TABLE I. GEOMETRIC MEAN RETURNS

\begin{tabular}{|c|c|c|c|c|}
\hline \multirow{2}{*}{ Outcome } & \multicolumn{4}{|c|}{ Securities } \\
\cline { 2 - 5 } & $\boldsymbol{A}$ & $\boldsymbol{B}$ & $\boldsymbol{C}$ & $\boldsymbol{D}$ \\
\hline 1 & 0.90 & -0.15 & -0.24 & 0.18 \\
\hline 2 & -0.40 & 0.35 & 0.60 & 0.22 \\
\hline $\begin{array}{c}\text { Geometric } \\
\text { mean }\end{array}$ & 0.13 & 0.09 & 0.13 & 0.19 \\
\hline
\end{tabular}

(calculated by the author)

If one possible outcome is a return of -1 . then for that outcome $\left(1+R_{i j}\right)=(1-1)=0$. The geometric mean is the product of the $\left(1+R_{i j}\right)$. The whole product becomes zero if one element is zero. Thus, the geometric mean criteria would never select an investment with any probability of bankruptcy. While the portfolio that maximizes the geometric mean is likely to be highly diversified, it will not (except in special circumstances) be mean-variance efficient. There are two cases where mean-variance analysis is meaningful for locating the portfolio with the highest geometric mean return .

First, maximizing the geometric mean return is equivalent to maximizing the expected value of a log utility function. The $\log$ utility function is:

$$
U_{(w)}=\ln (w)
$$

The log utility function can be written as:

$$
\max E \ln \left(w_{1}\right)
$$

where:

$w_{1}$ - is end of period wealth, a random variable. Since utility functions are unchanged up to a linear transformation, if we let $\mathcal{W}_{0}$ stand for the funds the investor can invest, then we can write the problem as:

$$
\begin{gathered}
\max E\left[\ln \left(w_{1}\right)-\ln \left(w_{0}\right)\right]=\max E \ln \left(w_{1} / w_{0}\right) \\
\max E\left[\ln \left(w_{1}\right)-\ln \left(w_{0}\right)\right]=\max E \ln \left(1+R_{i}\right) \\
\max E\left[\ln \left(w_{1}\right)-\ln \left(w_{0}\right)\right]=\max \sum P_{i} \times \ln \left(1+R_{i}\right) \\
\max E\left[\ln \left(w_{1}\right)-\ln \left(w_{0}\right)\right]=\max \sum \ln \left(1+R_{i}\right)^{P_{i}}
\end{gathered}
$$

We know that if returns are normally distributed, then mean variance portfolio analysis is appropriate for investors interested in maximizing expected utility. Investors with log utility functions are such investors. Thus, investors interested in maximizing the geometric mean return could use mean-variance analysis if returns were normally distributed. It has also been shown that the portfolio that maximizes the geometric mean return is mean-variance efficient if returns are log-normally distributed.

The next, we are going to do the systematic fundamental factor models. Fundamental factor models use company and industry attributes and market data as raw descriptors. Examples are price-earnings ratios, book-price ratios, estimated economic growth, and trading activity. The inputs into a fundamental factor model are stock returns and the raw descriptors about a company. Those fundamental variables about a company that are pervasive in explaining stock returns are, then, the raw descriptors retained in the model. Using cross-sectional analysis, the sensitivity of a stock's return to a raw descriptor is estimated. Two examples of commercially available fundamental factor models are the ones developed by BARRA and by Wilshire Associates [2, p.301-305]. The BARRA E2 model begins with raw descriptors. It then combines descriptors to obtain risk indices to capture related company attributes. For example, raw descriptors such as debt-to- asset ratio, debtto-equity ratio, and fixed-rate coverage are measures that capture a company's financial leverage. These measures would be combined to obtain a risk index for financial leverage. The BARRA E2 model is BARRA`s secondgeneration U.S. equity model. In 1997, BARRA released its third-generation model (BARRA E3). The discussion in this article and the information provided in the tables relating to the BARRA model and its output are based on the BARRA E2 model. The E3 model closely resembles the E2 model in structure, but with improved industry and risk index definitions. The BARRA E2 fundamental factor model has 13 risk indices and 55 industry groups. For 12 of the risk indices and the 55 industry groups, the model is estimated for BARRA's HICAP universe using statistical techniques [8]. Table 2 (as a fragment of studding) reproduces the information about the 13 risk indices as published by BARRA [1;2]. 
TABLE II. BARRA E2 MODEL RISK INDEX DEFINITIONS (FRAGMENT)

\begin{tabular}{|c|c|}
\hline Definitions & Meaning \\
\hline $\begin{array}{l}\text { 1. Variability in Markets } \\
\text { (VIM) }\end{array}$ & $\begin{array}{l}\text { This risk index is a predictor of the volatility of a stock based on its behavior and the behavior of its options in the capital } \\
\text { markets. BARRA uses different formulas for three categories of stocks: } \\
\text { - optioned stocks - all stocks having listed options; } \\
\text { - listed stocks - all stocks in the HICAP universe that are listed on an exchange but do not have listed options; } \\
\text { - thin stocks - all stocks that are traded over the counter or are outside the HICAP universe, except those with listed } \\
\text { options. }\end{array}$ \\
\hline 2. Success (SCS) & $\begin{array}{l}\text { The Success index identifies recently successful stocks using price behavior in the market (measured by historical alpha and } \\
\text { relative strength) and, to a lesser degree, earnings growth information. The relative strength of a stock is significant in } \\
\text { explaining its volatility: } \\
\text { + Relative Strength } \\
\text { +Recent Earnings Change } \\
\text { +IBES Earnings Growth } \\
\text {-Dividend Cuts, } 5 \text { years } \\
\text { +Growth in Earnings per Share }\end{array}$ \\
\hline 3. Size (SIZ) & $\begin{array}{l}\text { The Size index values total assets and market capitalization to differentiate large stocks from small stocks. This index has } \\
\text { been a major determinant of performance over the years as well as an important source of risk. }\end{array}$ \\
\hline 4. Trading Activity (TRA) & $\begin{array}{l}\text { Trading activity measures the relative activity of a firm's shares in the market, or the "institutional popularity" of a } \\
\text { company. The most important descriptors are the share turnover variables. In addition, this index includes the ratio of } \\
\text { trading volume to price variability, the logarithm of price, and the number of analysts following the stock, as reported in the } \\
\text { IBES database. The stocks with more rapid share turnover, lower price, and signs of greater trading activity are generally } \\
\text { the higher risk stocks. } \\
\text { + Annual Share Turnover } \\
\text { +Quarterly Share Turnover } \\
\text { + Share Turnover, } 5 \text { years } \\
\text { +Log of Common Stock Price } \\
\text { +IBES Number of Analysts + Trading Volume to Variance }\end{array}$ \\
\hline & \\
\hline $\begin{array}{l}\text { 8. Earnings Variability } \\
\text { (EVR }\end{array}$ & $\begin{array}{l}\text { The Earnings Variability index measures a company's historical earnings variability and cash flow fluctuations. In addition } \\
\text { to variance in earnings over five years, it includes the relative variability of earnings forecasts taken from the IBES } \\
\text { database, and the industry concentration of a firm's activities. }\end{array}$ \\
\hline $\begin{array}{l}\text { 9. Financial Leverage } \\
\text { (FLV) }\end{array}$ & $\begin{array}{l}\text { The Financial Leverage index captures the financial structure of a firm as well as its sensitivity to ir - rates using the debt to } \\
\text { assets ratio, the leverage at book value, and the probability of fixed charge - being covered. Bond market sensitivity is } \\
\text { included only for financial companies. }\end{array}$ \\
\hline 10. Foreign Income (FOR) & $\begin{array}{l}\text { This index reflects the fraction of operating income earned outside the United States. It is a measure of sensitivity to currency } \\
\text { exchange rate changes. }\end{array}$ \\
\hline 11. Labor Intensity (LBI) & This index estimates the importance of labor, relative to capital, in the operations of a firm. \\
\hline 12. Yield (YLD) & The Yield index is simply a relative measure of the company's annual dividend yield. \\
\hline 13. LOCAP & $\begin{array}{l}\text { The LOCAP characteristic indicates those companies that are not in the HICAP universe. It permits the fa } \\
\text { to be applied across a broader universe of assets than that used to estimate the model. }\end{array}$ \\
\hline
\end{tabular}

Also shown in the table are the raw descriptors used to construct each risk index. Before each raw descriptor in Table 2 is a plus or minus sign. The sign indicates how the raw descriptor influences a risk index. For example, the earnings-to-price ratio is a combination of the following raw descriptors: current earnings-to-price ratio, earnings-to-price ratio for the past 5 years, and $\mathrm{I} / \mathrm{B} / \mathrm{E} / \mathrm{S}$ earnings-to-price ratio projection. As with the macroeconomic factor model, the raw descriptors are standardized or normalized. The risk indices are in turn standardized. The sensitivity of each company to each risk index is standardized. The Wilshire Atlas factor model uses six fundamental factors, one market factor sensitivity, and 39 industry factors to explain stock returns. The seven fundamental factors and the market factor sensitivity are listed in Table 3, along with their definitions. The BARRA and Wilshire factor models are commercially available. Now we'll look at a proprietary model developed by a firm for its own use in managing client equity portfolios - Goldman Sachs Asset Management (GSAM). This firm is the investment management subsidiary of Goldman Sachs \& Co., a broker/dealer firm. There are nine descriptors used in the GSAM factor model. The descriptors that are the factors in the model are described in Table 3. The factors fall into three categories: value measures, growth and momentum and risk measures.
Let's research the output and inputs of a factor model. Now that we have identified the types of factor models, let's look at the output of the model and the inputs to the model after the estimation has taken place. The output of a factor model is found by first multiplying factor sensitivity by the assumed value for the factor measure (assumed risk factor). This gives the contribution to the model's output from a given risk factor exposure. Summing up over all risk factors gives the output. For a K-factor model, this is expressed mathematically as follows:

$$
\begin{aligned}
& \text { Output }=\text { Beta }_{1}\left(\text { Factor }_{1} \text { measure }\right)+ \\
& + \text { Beta }_{2}\left(\text { Factor }_{2} \text { measure }\right)+ \\
& +\ldots \text { Beta }_{K}\left(\text { Factor }_{k} \text { measure }\right)
\end{aligned}
$$

Let's look first at the betas. These are the factor sensitivities and are estimated statistically. As explained earlier, they are commonly standardized or normalized. The output varies by model. For example, in the BIRR macroeconomic factor model, the output is the expected excess return given the estimated factor sensitivities and the assumed values for the factor measures. The expected excess return is the expected return above the risk-free rate. In contrast, in the Salomon RAM fact model, the output is a score that is used to rank the outcome given the estimated 
factor sensitivities and assumed values for the factor measures. The factor measures vary by model. In the BIRR macroeconomic factor model, for example, a factor measure is the estimated market price of the risk factors expressed in percent per year. For the Salomon RAM factor model, a factor measure is the normalized value for the factor [4].

The choice of managerial decision on the set of alternatives is essentially limited to the difficulty of forming

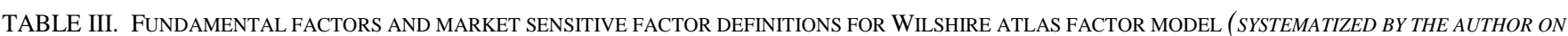
$[6 ; 7 ; 8 ; 9])$

\begin{tabular}{|c|c|}
\hline Fundamental factors & Meaning \\
\hline 1.Earnings/price ratio & Sum of the most recent four quarters' earnings per share divided by the closing price. \\
\hline 2. Book value/price ratio & Book value divided by common equity shares outstanding. \\
\hline 3. Market capitalization & The natural logarithm of the product of a security's price multiplied by the number of shares outstanding. \\
\hline 4. Net earning revision & $\begin{array}{l}\text { Analysts momentum measure: Net earnings revision, based on I/B/E/S data, measures analysts' optimism of earnings. Net } \\
\text { earnings revision is the percentage of analysts who are feeling more optimistic about earnings in the next period. The higher } \\
\text { the net earnings revision number, the more optimistic analysts are about an increase in that company's earnings. }\end{array}$ \\
\hline 5. Reversal & $\begin{array}{l}\text { Price momentum measure: Reversal captures the mean reversion tendencies of stocks. It is a measure of the difference } \\
\text { between a security's actual return in the last period and the expected return with respect to its beta. If a stock has a positive } \\
\text { reversal this means that it had a higher than expected return in the last period given its beta. Thus, this security is expected to } \\
\text { have a lower than expected return in the next period so that the returns for this security will conform to the norm } \\
\text { expectations over the long run. }\end{array}$ \\
\hline 6. Earnings torpedo & $\begin{array}{l}\text { Earnings momentum measure: Earnings torpedo, based on } \mathrm{I} / \mathrm{B} / \mathrm{E} / \mathrm{S} \text { data, is a measure of the estimated growth in earnings for } \\
\text { a security relative to historical earnings. Earnings torpedo is based on the ratio of next year's estimated earnings per share } \\
\text { versus its historical earnings per share. The securities in the universe are then ranked by the estimate and given an earnings } \\
\text { torpedo score. A security with a high earnings torpedo score is considered to be vulnerable to a large drop in price if earnings } \\
\text { do not meet the higher earnings estimates forecasted by analysts in the next period. }\end{array}$ \\
\hline 7. Historical beta & $\begin{array}{l}\text { Classic measure of security volatility. Measured for each security by regressing the past } 60 \text { months' worth of excess returns } \\
\text { against the S\&P500. A minimum of } 38 \text { months are required for the data to be valid. }\end{array}$ \\
\hline
\end{tabular}

In the process modelling of international strategies, innovative forms of investment are widely used: crowdfunding, crowdinvesting, crowdsourcing [10]. Crypto currency is the subject form of strategy and innovative dominant of monetary policy. Crowdfunding acts as the new instrument of investment of innovative projects in the modern business environment. Advantages to the businessman from the sector of small and medium business can be defined through crowd funding which is capable to provide unique support for existence of businessmen at several levels [11]. Innovative technologies of large-scale investment process form crowdsourcing - is the process of merging financial resources with the help of information platforms to solve business problems, moreover the factor of geographical remoteness of subjects works. World practice identifies two possible categories of crowdsourcing [10;11]: on the sphere of life (business, social, political); and as solvable tasks (creation of a product (content), vote, search of the decision, search of people, collection of information, collecting opinions, testing, support service, fund raising crowdfunding). Today, in modern international practice, a new innovative monetary policy tool has emerged - the crypto currency - is a type of digital currency whose issuance and accounting is based on asymmetric encryption and the use of various cryptographic protection methods. It is a kind of digital money based on cryptography technology, that is, data encryption and does not have a physical appearance, and exists only in electronic form. Its main features are anonymity, decentralization and security. Crypto currencies are functioning decentralized in a distributed computer network. They are not in the banknotes that you could touch. They exist in the digital world. Total crypto currency on our planet has already been invented and created about a thousand. The main experts allocate up to a single criterion, which covers different, and in some cases, conflicting requirements. Additional complications are the need to take into account and formalize the uncertainty of both source data and purposes. These lead to the need for use of such models of description of the reality, that allow to process large amounts of data in conditions of the growth of uncertainty [5]. 


\section{CONCLUSIONS AND PROPOSALS}

The source of information for the process modeling of international strategies is the forecasts of scientific, technical and socio-economic development, industry forecasts, and the results of marketing research. The author's interest is directed to the process of developing immunization strategies. In practice, the synthesis of active and immunisation strategies is used. You can use a combination of active and immunisation strategies. The competitive advantage of the immunization strategy is that the line manager either actively and easily manages the portfolio in the external market or immunizes it in the domestic market. These two types of strategies are implemented in parallel. At the same time, conditional immunization does not act as a synthesis of strategies. There are three types of factor models: statistical factor models, macroeconomic factor models, and fundamental factor models. Statistical factor models use principal components analysis to analyze stock returns to determine statistical factors that best explain those returns. Consequently, the statistical factor model is rarely used in practice. The more common factor models are the macroeconomic factor model and the fundamental factor model. In a factor model, the sensitivity of a stock to a factor is estimated. The risk exposure profile of a stock is identified by the set of factor sensitivities. The risk exposure profile of a portfolio is the weighted average of the risk exposure profile of the stocks in the portfolio. Similarly, the risk exposure profile of a market index can be obtained. The output of a factor model can be either the expected excess return or a scenario score. The expected excess return of a stock is found by multiplying each factor sensitivity by the assumed value for the risk factor and summing up over all the risk factors. The expected return is the expected excess return plus the risk-free rate. The expected excess return for a portfolio and a market index is just the weighted average of the expected excess return of the stocks comprising the portfolio or the market index. The power of a factor model is that given the risk factors and the factor sensitivities, a portfolio's risk exposure profile can be quantified and controlled. Applications of factor models include the ability to assess whether or not the current portfolio is consistent with a manager's strengths, and to construct a portfolio with a specific tilt without making unintentional bets. Since many factors in a fundamental model are the same characteristics used in style management, factor models can be used in controlling risk in a style management strategy. Factor models can also be used by equity index managers to more effectively control the risk of an indexed portfolio to minimize tracking error. The output of a dividend discount model can be used as a factor in a model. The paper explores innovative strategic technologies such as crowdfunding, crowdinvesting, crowdsourcing. Nowadays crowdfunding gains steam and become one of the most convenient and popular ways of collecting investments for a startup projects. Successful foreign practice was studied and the prerequisites for the development of crowdinvesting platforms on the Ukrainian investment market were highlighted. Summing up the research of this problem, the authors note that the modeling of the strategy of the enterprise development, industry, region, territory, and country is a complex system process, which is based on a specific subject area, founds the specifics and features of the research object. The apparatus of economic and mathematical methods allows constructing and calculating an estimate of the strategy efficiency as a whole or a strategic plan for the implementation of the investment project, while imposing a control function. It is suggested that the systematic of fundamental factor models are proposed and the fact of globalization of the economy is taken into account. This paper considers the variation of process modelling of international strategies using the economic and mathematical tools for assessing the effectiveness of implementation and further optimization.

\section{ACKNOWLEDGEMENT}

The scientific and methodical tools have been implemented: by the Executive Committee of the Odessa City Council in the form of "Scientific and methodological recommendations to local authorities regarding the evaluation of the effectiveness of investment projects under the conditions of compliance control (certificate No. 12.2-16 outgoing number / 890 dated December 6, 2016, Act No. 21 / 01-12 / D dated September 1, 2016); Department of Economic Development of Odessa City Council (certificate No. 2565 / 01-41 dated December 5, 2016) during the development of the Strategy of Economic and Social Development of Odessa City until 2022, Program of SocioEconomic and Cultural Development of Odessa City in 2020, Investment Strategy "Odessa 5T".

\section{REFERENCES}

[1] J. Elton Edvin, J. Gruber Martin, J. Brown Stephen, and N. William Goetzmann, Modern Portfolio. Theory and Investment Analysis, 7-th Edition. - USA: New York: Hamilton Printing Company, 2014.

[2] J. Frank Fabozzi, CFA, Investment management, 2nd ed. - USA, New Jersey: Prentice-Hall, Inc., 2008

[3] N. Ilysheva, and S. Krylova, Accounting, Analysis and Strategic Management of Innovation Activity. Moscow: Finances \& Statistics, 2014.

[4] T. Hilorme, L. Karpenko, O. Fedoruk, I. Shevchenko, and S. Drobyazko, "Innovative methods of performance evaluation of energy efficiency project", Academy of Strategic Management Journal, 2018, vol. 17, no 2, pp.1-10.

[5] P. Hryhoruk, and N. Khrushch, "An approach to construct fuzzy preference relationships for managerial decision making", Scientific Bulletin of Polissia, vol. 4, no 12, pp. 92-99, 2017.

[6] L. Lipkova, "Innovation Policy of the European Union". In Honova, I., L.Melecky and M.Stanickova (ed). Proceeding of the $1^{\text {st }}$ International Conference on European Integration 2012. Ostrava: VSB-Technical University of Ostrava, 2012, pp. 171-178.

[7] M. Stanickova, "Assessment of Efficiency in Selected EU Member States by Data Envelopment Analysis Models". In Honova, I., L.Melecky and M.Stanickova (ed). Proceeding of the $1^{\text {st }}$ International Conference on European Integration 2012. Ostrava: VSB-Technical University of Ostrava, 2012, pp. 303-314.

[8] A. John Pearce, "Strategic management: formulation, implementation and control", 8th ed. - USA, New Jersey: Publications Office of the McGraw-Hill Companies, 2013.

[9] B. Navratil, "Ever-Coser or Multi-Speed Union". In Kovarova, E., L.Melecky and M.Stanickova (ed). Proceeding of the $3^{\text {st }}$ International Conference on European Intergration 2016. Ostrava: VSB-Technical University of Ostrava, 2016, pp. 649-655.

[10] L. Karpenko, P., and Voronzhak, "Base alternatives and the paradigm of impact investing development in the coordinates of globalization changes and euro integration". In: Proceedings of the 4th International Conference on European Integration 2018. Ostrava: VSB Technical University of Ostrava, 2018, pp.659-668.

[11] E. Mollick, "The Dynamics of Crowdfunding: An Exploratory Study". Journal of Business Venturing, vol. 29, Iss. 1. [Online]. Available: https://papers.ssrn.com/sol3/papers.cfm?abstract_id =2088298\#\#

[12] E. Kovarova, "Value and Commodity Structure of the West Africa`s Exports to the European Union". In Kovarova, E., L.Melecky and M.Stanickova (ed). in Proceeding of the $3^{\text {st }}$ International Conference on European Intergration 2016. Ostrava: VSB-Technical University of Ostrava, 2016, pp. 480-488. 